Review

\title{
Local Food Campaign in a Globalization Context: A Systematic Review
}

\author{
Susan (Sixue) Jia
}

Citation: Jia, S. Local Food Campaign in a Globalization Context: A Systematic Review. Sustainability 2021, 13, 7487. https://doi.org/ $10.3390 /$ su13137487

Academic Editors: Vera Teresa Foti, Marzia Ingrassia and Claudio Bellia

Received: 5 June 2021

Accepted: 2 July 2021

Published: 5 July 2021

Publisher's Note: MDPI stays neutral with regard to jurisdictional claims in published maps and institutional affiliations.

Copyright: (C) 2021 by the author. Licensee MDPI, Basel, Switzerland. This article is an open access article distributed under the terms and conditions of the Creative Commons Attribution (CC BY) license (https:// creativecommons.org/licenses/by/ $4.0 /)$.
School of Finance and Business, Shanghai Normal University, Shanghai 200234, China; s_jia@shnu.edu.cn

\begin{abstract}
As a basic commodity, food has undergone thorough globalization, with the global food market totaling 1392 billion USD in 2019. Despite such a great amount of global food trade, the idea of favouring the consumption of local food, or local food campaigns, has won ever growing attention and advocacy in recent years as an effort to enhance social and environmental sustainability. This systematic review study draws wisdom from the extant literature and provides critical thinking on how local food differs from non-local food and whether the two are more antagonistic or more complementary. Results suggest that although the term "local food" has hardly been clearly defined, it is possible to accommodate different opinions in a set of common constructs in Eriksen's "three domains of proximity". Regarding the strengths of local food, researchers agree more on its strong personal connection, distinctive culture, and high quality, but less on its supporting local economy, reduced energy consumption, and environmental friendliness. Meanwhile, local food has its current weaknesses in terms of higher price and unsuccessful information communication; however, these are not without solutions. Overall, while food localization and globalization differ in purpose, they can well co-exist, promote collaboration rather than confrontation, and together accelerate the sustainable growth of the food market.
\end{abstract}

Keywords: local food; globalization; proximity; strength; weakness; co-exist

\section{Introduction}

Globalization has transnationally decoupled commodity consumption from production, multiplying customer choices in the importing countries and proliferating revenue streams back to the exporting countries. As a basic commodity, food has undergone thorough globalization, with the global food market totaling 1392 billion USD in 2019 [1]. Despite such a great amount of global food trade, the idea of favouring consumption of local food, or local food campaign, has won ever growing attention and advocacy in recent years as an effort to enhance social and environmental sustainability [2-5]. Whether the two food systems should compete or collaborate remains an open question.

To be able to answer the question, one must first clearly define local food, then analyze its advantages and disadvantages, and finally compare it with non-local food. Unfortunately, researchers have different opinions regarding how to define local food [6-9]. Worse still, existing studies have been glutted with opposite arguments on whether local food really has advantages [7,10-14]. Without clarifying these fundamental issues, it could be hard to position local food campaigns in a globalization context.

To this end, this study aims at drawing wisdom from the extant literature and providing critical thinking on how local food differs from non-local food and whether the two are more antagonistic or more complementary. Specifically, this study unfolds as follows: Section 2 describes the systematic review methodology; Section 3 introduces several constructs that help characterize local food under a common research framework; Section 4 explores the strengths of local food and reconciles opposing opinions; Section 5 provides potential solutions to the current weaknesses of local food; Section 6 discusses how local and non-local food may co-exist to better serve local customers, and the final section comprises a summary of the findings. 


\section{Systematic Review Methodology}

A systematic review was performed per the preferred reporting items for systematic review and meta-analysis (PRISMA) 2020 checklist [15], with Web of Science being the sole database. Figure 1 depicts the searching strategy of this study, with Table 1 reporting the exact queries and the number of results returned as of 30 March 2021.

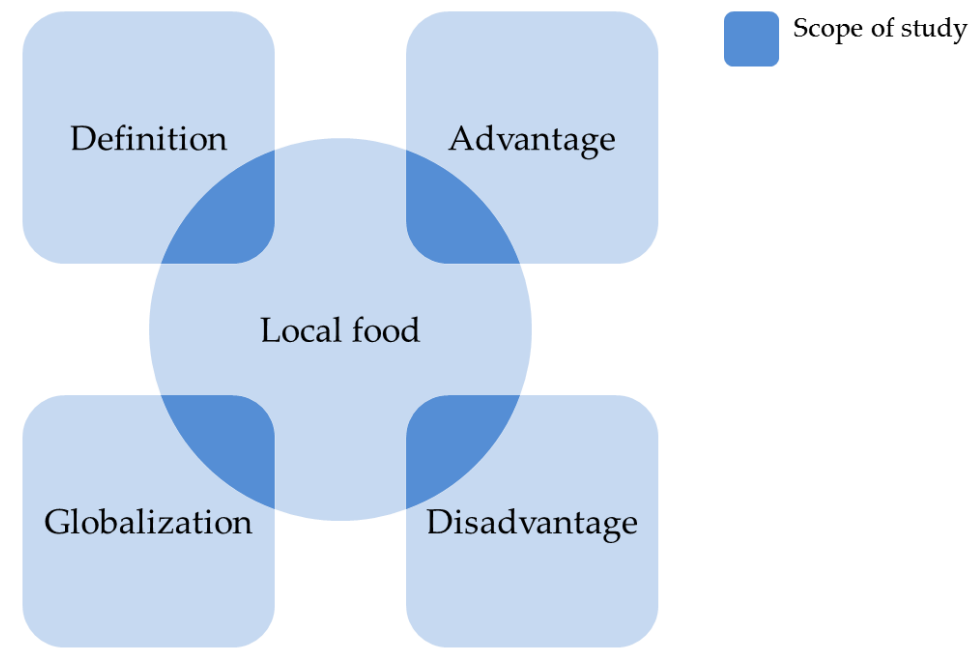

Figure 1. Searching strategy.

Table 1. Search queries and the number of results returned.

\begin{tabular}{ccc}
\hline Search Logic & Search String & No. of Results \\
\hline Definition & TS ${ }^{1}=$ "local food" AND defin* & 369 \\
Advantage & TS = "local food" AND advantage & 124 \\
Disadvantage & TS = "local food" AND disadvantage & 84 \\
Globalization & TS = "local food" AND globaliz* & 144 \\
& \multicolumn{2}{c}{ Total } \\
\hline
\end{tabular}

${ }_{1}^{1} \mathrm{TS}=$ Topic.

From the 721 results, 39 duplicate records were removed. For example, if a study contained "local food", "advantage", and "globalization" in its topic, it would be searched twice, with means that one of the records had to be removed to avoid duplication. The remaining 682 records went into the screening process, as is illustrated in Figure 2. Finally, 57 records have been included in this study. 


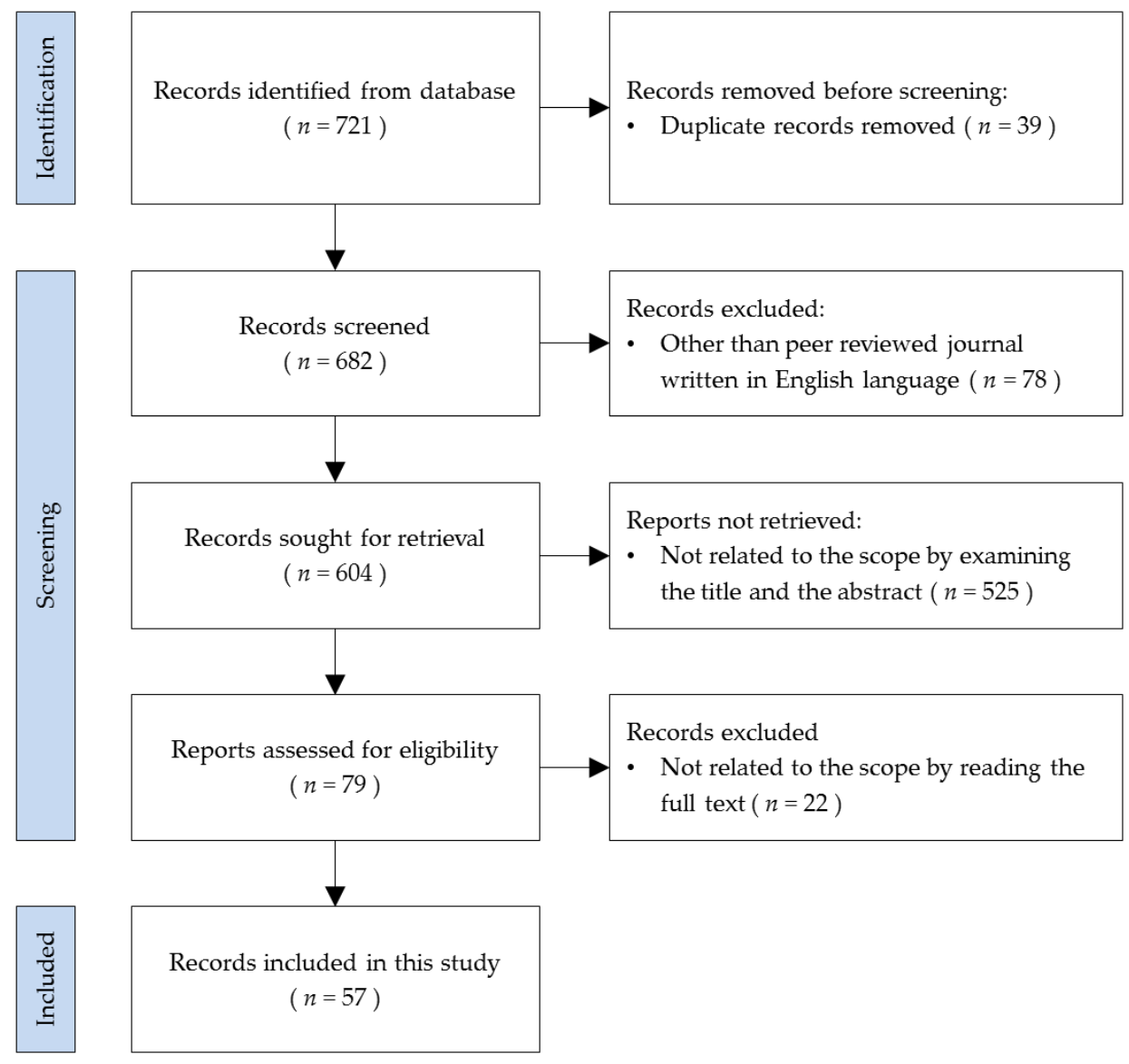

Figure 2. Flow chart.

\section{Local Food: A Research Framework Rather Than a Clear Definition}

The term "local food" has hardly been clearly defined [6-9]. Nevertheless, researchers have mostly agreed that the following forms of marketing initiatives or campaigns fall into the category of local food, including but not limited to short food supply chains (SFSCs), community supported agriculture (CSA), direct farmer-to-retailer, farmers' markets, farmer shops, on-farm or digital direct sales, and box schemes [2,16,17]. From a business point of view, the lack of a clear definition of local food is not necessarily a huge problem, because customers have their own interpretation of "local" which can be very specific [6], such that it might be even better to directly mark the origin of the food with the name of the farm or region $[18,19]$, rather than taking the risk of overwhelming the customers with ambiguous labels [8]. However, from an academic point of view, in order to narrow the scope of local food and make relevant studies more comparable, researchers have found it helpful to characterize local food under a common research framework with multiple constructs, albeit not a set of more explicit indicators.

Among the various constructs proposed in the extant studies, Eriksen's [20] "three domains of proximity" is neatly formulated in terms of both mutual exclusivity and collective exhaustivity. On the one hand, each of the three domains, namely geographical proximity, relational proximity, and values of proximity, examines a distinct aspect of local food. On the other hand, the three domains well encompass the constructs proposed by other studies.

Geographical proximity is the most incontrovertible construct that defines local food [6,13,16,21-25]. Morris and Buller [26] have considered local food as "food produced, processed and retailed within a geographically circumscribed area defined in various ways". The circumscription is indeed varied, with previous local food studies focusing on 
a city [27], a region [2,3,13], a province [25], a state [9], or an entire nation $[5,21,28]$. These suggest the opposite of local food is not always globalized food.

Relational proximity refers to the direct interactions between a food producer and a food consumer. When local food flows through direct marketing channels such as farmers' markets and box schemes, it creates a strong connection between farmers and consumers $[23,24]$, which is unlikely to be developed in conventionally longer supply chains where additional intermediaries such as wholesalers get involved [16,20]. Relational proximity is sometimes attributed to geographical proximity. To be specific, on the one extreme where food is produced in the vicinity of the consumers, face-to-face selling is an economical practice which enhances the relation [29]. On the other extreme, where there is a long distance from farm to table, it is more cost-effective for the farmers to engage intermediaries although this weakens the relation [16].

Values of proximity examine the impact of food on health, environment, society, and culture. Local food is believed to be produced using the best quality ingredients [24], with reduced use of synthetic chemicals and energy-based fertilizers [30]. Therefore, local food is perceived as both safer [2] and low-carbon [5]. Moreover, local food campaign is also believed to enhance local economies [2] and culture [25]. Over the years, there have been heated debates about the actual values of local food. For example, researchers tend to agree on the social benefits of SFSCs, but less on their economic and environmental outcomes [16]. All of these will be discussed in detail in Section 4. Nevertheless, the heated debates exactly justify values of proximity as a generally acknowledged construct to analyze local food.

Aided by these constructs that tell local food from non-local food, researchers have been conducting studies on specific food types, as are listed in Table 2 . The food category in the first column is adapted from reference [1]. Seven typical studies have been chosen as examples, with a " $\sqrt{ }$ " indicating that a study involves a food category. The geographical focus of a study is reported in the parenthesis. For example, Rucabado-Palomar and Cuellar-Padilla's [25] local food study, focusing on a province, involves dairy products and birds' eggs, meat and meat preparations, and vegetables and fruits. It is roughly concluded from Table 2 that studies focusing on geographically smaller areas involve more types of food, whereas studies focusing on geographically larger areas involve fewer types of food. This is quite reasonable because the larger a studied area, the more likely it holds diverse natural resources that nurture more types of food locally with a competitive advantage, which lessens the necessity of food import and the resulting conflict of local and non-local food.

Regardless of food type, if local food provides the same perceived benefit as non-local food while charging a lower price, there is no need to "save" local food because it has competitiveness in the food market. By perceptiveness, it is emphasized that the benefit has to be acknowledged by the end customers. The same is true with the situation when local food charges the same price as non-local food but offers additional perceived benefit. However, when local food fails to compete with non-local food, researchers come forward to claim either the latent benefit of local food or the invisible cost of non-local food, as are addressed in the next section. 
Table 2. Food category involved in some local food studies, geographical focus in parentheses.

\begin{tabular}{|c|c|c|c|c|c|c|c|}
\hline Food Category [1] & $\begin{array}{c}\text { Ref. [27] } \\
\text { (City) }\end{array}$ & $\begin{array}{l}\text { Ref. [13] } \\
\text { (Region) }\end{array}$ & $\begin{array}{c}\text { Ref. [2] } \\
\text { (Region) }\end{array}$ & $\begin{array}{c}\text { Ref. [3] } \\
\text { (Region) }\end{array}$ & $\begin{array}{c}\text { Ref. [25] } \\
\text { (Province) }\end{array}$ & $\begin{array}{l}\text { Ref. [21] } \\
\text { (Nation) }\end{array}$ & $\begin{array}{l}\text { Ref. [28] } \\
\text { (Nation) }\end{array}$ \\
\hline \multicolumn{8}{|l|}{ Animal and vegetable oils, fats and waxes } \\
\hline Beverages & & $\sqrt{ }$ & & & & & \\
\hline Coffee, tea, cocoa, spices and manufactures thereof & & & & & & & \\
\hline Dairy products and birds' eggs & $\sqrt{ }$ & $\sqrt{ }$ & $\sqrt{ }$ & $\sqrt{ }$ & $\sqrt{ }$ & $\sqrt{ }$ & \\
\hline Fish, crustaceans, molluscs and preparations thereof & $\sqrt{ }$ & $\sqrt{ }$ & $\sqrt{ }$ & & & & \\
\hline Meat and meat preparations & $\sqrt{ }$ & $\sqrt{ }$ & $\sqrt{ }$ & & $\sqrt{ }$ & & \\
\hline $\begin{array}{l}\text { Oilseeds and oleaginous fruits } \\
\text { Sugar sugar prenarations }\end{array}$ & & & & & & & \\
\hline Vegetables and fruits & $\sqrt{ }$ & $\sqrt{ }$ & $\sqrt{ }$ & & $\sqrt{ }$ & & $\sqrt{ }$ \\
\hline
\end{tabular}




\section{Exploring Local Food Strengths}

Local food, featuring high relational proximity and high perceived values of proximity, is expected to gain many strengths over non-local food. These strengths include strong personal connection, distinctive culture, high-quality product, supporting local economy, reduced energy consumption, and environmental friendliness [5,31-36]. Accordingly, consumers enthusiastic for locally-produced food or food with a clear regional provenance are willing to pay a price premium [6], and in the meantime, farmers are adding value and retaining a bigger slice of the retail price [7]. However, whereas some of the strengths of local food have been well accepted by the research community, others have received much criticism [7,10-14]. Therefore, the exploration of the strengths of local food has to be accompanied by careful interpretation.

The strong personal connection and distinctive culture established by local food are helping it gaining continuous momentum [2]. As a direct result of relational proximity, local food marketing fosters social contact between farmers and consumers, building trust, and contributing to the social capital of a region [32,36]. Taken broadly, local food also enhances the personal and emotional connection of the customers with the historical, cultural, and territorially incorporated values of the region [3]. The benefit of such connections is twofold. From a business perspective, local food producers can subsequently build up a longterm relationship with their customers, operate cost-effectively and optimally, and reinforce customer loyalty $[25,33,35]$. The producers may also interpret and negotiate regional food culture as a selling point for their businesses [31]. From a lifestyle perspective, not only do customers regard farmers' markets as a third place where they have the opportunity to interact with others, nourishing a broader appreciation for public life and space [37], but the producers are also willing to participate to turn the market into an exhibition of their products and gain direct feedback from customers, though they do have additional outlets for their products [32].

Besides connection and culture, quality is another dimension where researchers mostly agree that local food has an edge. Both clarity of origin and shorter farm-to-table distance reassure the customers of the reliability of the producer [3,38], which further leads to the belief that local food signifies high quality, manifested as freshness, nutritional value, taste, and appearance $[13,16,25,27,32]$. Local food is also perceived as healthier, unprocessed, and containing fewer preservative compounds $[5,36]$, because local food is produced and handled for the purpose of better taste rather than longer shelf life [33], and is less likely to be contaminated by bacteria or germs [36]. In comparison, customers are skeptical about the packaging of food products involving the use of modern technologies [5]. Technically, whether local food is intrinsically healthier than non-local food remains an open question, with the term healthier itself hard to quantify. Therefore, "healthier local food" seems more a marketing positioning than a scientific fact.

The argument that supporting local food helps support local economy has received both advocacy and criticism. Advocates claim that consuming local food enhances local economic development $[2,27,34,35,39]$, with the word "revitalizing" appearing in much of the literature [32-34,40]. One direct contribution of local food campaign is keeping many farmers in business [25,32,41,42], especially for small- and medium-sized farms [25], and subsequently improving the welfare of farmers and farming communities [43-45]. The other indirect contribution is triggering more economic activity in the region, termed as multiplier effect that an extra dollar paid to a local food farmer will be subsequently paid by this farmer for other products and services in the local economy, generating a cyclic local business and job market $[14,33]$. However, such scattered agriculture from small farms produced in the vicinity of where it is consumed contravenes the purpose of feeding more people better food in an economical way [14], with Nilsson [32] emphasizing that smaller businesses could be less labor intensive and cost effective, which raises the operational costs of a business and lowers the profit level. To put it another way, without taking advantage of economy of scale, local food produced by small farms is selling at a higher price, signifying an inefficient mode of resource utilization. Therefore, Scharber 
and Dancs [14] demonstrated that, rather than drawing benefits from a virtuous circle of local spending, resources are more efficiently used to create greater wealth by exploiting comparative advantage and trade. The major gap between these two opposite views is that critics are seeking a global optimum solution based on idealized assumptions such as the flexible switch from producing one good to another, whereas the advocates are defending the local best practice in a real-life context. Any attempt to reconcile the two opinions must refine existing economic theory to capture the multilevel nature of this problem.

Reduced energy consumption and environmental friendliness are the most controversial advantages of local food argued by researchers. On the positive side, local food is perceived as requiring fewer natural resources and causing less emission, leading to a lower environmental footprint $[5,46]$. This is largely because local food converges food production and consumption and reduces "food miles" [47], while a conventional food system is often associated with longer food miles [48]. However, on the negative side, it is argued that although the distances traveled by local food are a lot shorter, the vehicles used are not as energy efficient as the vehicles used in the long-distance transportation system for imported products [22,32]. Besides, food transportation generally represents less than $15 \%$ of the total energy used to produce food products [22,49], with McWilliams [50] (p. 18) metaphorically addressing the food mile concept as "a bit player in the larger drama". For example, the life cycle of tomato products is decomposed into total agriculture, processing, bulk packaging, bulk transport, remanufacturing, consumer packaging, and transport to distributor [49]. Instead of importing tomatoes from Spain which has a comparative advantage, the extra energy and fertilizer required to grow tomatoes in greenhouses in Sweden [22] or the UK [14] overwhelm the emissions savings from reduced transport. Similarly, importing dairy products, lamb, and onions from New Zealand is more energy efficient than locally producing them in the UK [51]. Overall, food mile alone is a poor indicator of the environmental impacts of food production from a life cycle perspective, and the claimed benefit of reduced energy consumption and environmental friendliness of local food requires comprehensive calculation.

To summarize, researchers tend to agree on the social and health benefits of local food, and less on their economic and environmental outcomes. Given these strengths over non-local food, local food seems highly competitive. However, several weaknesses have limited the expansion of local food, as are discussed in the following section.

\section{Improving Local Food Weaknesses}

Perhaps the largest weakness of local food is its higher price, which restricts its online and offline selling, as well as its ordering in restaurants $[5,6,17,36]$. Loke et al. [52] predicted that the milk price in Hawaii, USA could increase by $17 \%$ if the production became totally local. One important reason for the higher price is the small scale of local food production [23,32]. Not only do small- and medium-sized farms forsake the advantage of economies of scale, but they also lack bargaining power with logistical suppliers downstream [25,34]. A potential remedy for the individually small scale is scaling up by bundling farms in terms of purchasing or logistics. Information technology and coordinated distribution methods are also expected to energize the regional food system [34]. These are where governments, chambers of commerce, and food hubs [53] come into play. Meanwhile, in addition to lowering unit cost, local food merchants are encouraged to educate their customers by proudly emphasizing the additional value for money in their products.

Another weakness of local food involves information communication. Potential customers of local food perceive product information uncertainties, manifested as being unsure about the taste, healthiness, origin, and variety of local food, or feeling the collection of such information should take a lot of time [54]. Consequently, effectively providing product information has a strong influence on customers' willingness to select local food [55-57]. However, individual farmers lack the marketing budget and skills to communicate the value of local food to potential customers [2,58]. Some hotels, albeit supporting 
local food, also fail to provide sufficient information about local foods to tourists [59]. Therefore, it is essential to establish a convenient communicative channel to facilitate the clear advertising of local food.

\section{Local Food Campaign and Globalization}

Local food campaign has long been regarded as an anti-globalization movement, with researchers and policy makers calling for protecting food sovereignty against the global food system [60]. This is largely because food globalization is having an adverse impact on small- and medium-sized farms [25], and has been widely acknowledged as unsustainable [16]. On a deeper level, food localism embodies a moral economy that promotes democratic participation and community building, whereas food globalization symbolizes a market economy that features capitalistic accumulation and technocratic rule [10]. After all, it is a trade-off between fairness and efficiency.

Although food localization and globalization differ in purpose, they can well co-exist, being more complementary than antagonistic [61,62]. Scharber and Dancs [14] stated that many regions that can efficiently grow vegetables during summer do not have a comparative advantage in winter months, such that adhering to local food throughout the year compromises the purpose of ensuring customers with year-round access to lowcost fresh foods. Tongarlak et al. [63] have also discovered an optimal strategy in their supply chain study featuring hybrid sourcing policy, with the distant large mainstream farms offering low-price stable supply and the local small farms supplementing as quick responses to demand fluctuation. Ultimately, the two systems are expected to reach equilibrium to better serve customers.

\section{Conclusions}

This systematic review study draws wisdom from the extant literature and provides critical thinking on how local food differs from non-local food and whether the two are more antagonistic or more complementary. Although the term "local food" has hardly been clearly defined, it is possible to accommodate different opinions in a set of common constructs. Regarding the strengths of local food, researchers agree more on its strong personal connection, distinctive culture, and high-quality product, but less on its supporting local economy, reduced energy consumption, and environmental friendliness. Meanwhile, local food has its current weaknesses in terms of higher price and unsuccessful information communication; however, these are not without solutions. Overall, while food localization and globalization differ in purpose, they can well co-exist, promote collaboration rather than confrontation, and together accelerate the sustainable growth of the food market.

The contribution of this study is three-fold. Firstly, it explicitly points out that local food needs a research framework rather than a clear definition. Based on Eriksen's "three domains of proximity", a set of common constructs, it provides validation and further interpretation. Secondly, this study suggests that existing economic theory of comparative advantage has its limitation when analyzing food localization. The multilevel nature of local food, ranging from seeking global optimum solution with idealized assumptions to defending the local best practice in a real-life context, calls for refining existing economic theory. Finally, this study encourages local food marketers to enhance value creation, communication, and delivery to offset the higher price of local food. By intently exploring its advantages in terms of socio-economic sustainability as well as high quality, local food will surely win a solid share in the globalized food market.

Funding: This research was funded by National Natural Science Foundation of China, grant number 72072118 .

Conflicts of Interest: The author declares no conflict of interest. 


\section{References}

1. Food Outlook: Biannual Report on Global Food Markets. Available online: http://www.fao.org/documents/card/en/c/ca950 9en/ (accessed on 1 July 2021).

2. Berner, S.; Derler, H.; Rehorska, R.; Pabst, S.; Seebacher, U. Roadmapping to enhance local food supply: Case study of a city-region in Austria. Sustainability 2019, 11, 3876. [CrossRef]

3. Nicolosi, A.; Lagana, V.R.; Laven, D.; Marciano, C.; Skoglund, W. Consumer habits of local food: Perspectives from northern Sweden. Sustainability 2019, 11, 6715. [CrossRef]

4. Warshawsky, D.; Vos, R. Governing at scale: Successful local food initiatives in the world's cities. Sustainability 2019, 11, 7226. [CrossRef]

5. Barska, A.; Wojciechowska-Solis, J. E-consumers and local food products: A perspective for developing online shopping for local goods in Poland. Sustainability 2020, 12, 4958. [CrossRef]

6. Lang, M.; Stanton, J.; Qu, Y. Consumers' evolving definition and expectations for local foods. Br. Food J. 2014, 116, 1808-1820. [CrossRef]

7. O'Neill, K.J. Situating the 'alternative' within the 'conventional': Local food experiences from the East Riding of Yorkshire, UK. J. Rural Stud. 2014, 35, 112-122. [CrossRef]

8. Granvik, M.; Joosse, S.; Hunt, A.; Hallberg, I. Confusion and misunderstanding: Interpretations and definitions of local food. Sustainability 2017, 9, 1981. [CrossRef]

9. Watson, P.; Cooke, S.; Kay, D.; Alward, G.; Morales, A. A method for evaluating the economic contribution of a local food system. J. Agric. Resour. Econ. 2017, 42, 180-194.

10. Hinrichs, C.C. The practice and politics of food system localization. J. Rural Stud. 2003, 19, 33-45. [CrossRef]

11. Milà i Canals, L.; Cowell, S.J.; Sim, S.; Basson, L. Comparing domestic versus imported apples: A focus on energy use. Environ. Sci. Pollut. Res. 2007, 14, 338-344. [CrossRef]

12. Edwards-Jones, G.; Canals, L.M.I.; Hounsome, N.; Truninger, M.; Koerber, G.; Hounsome, B.; Cross, P.; York, E.H.; Hospido, A.; Plassmann, K.; et al. Testing the assertion that 'local food is best': The challenges of an evidence-based approach. Trends Food Sci. Technol. 2008, 19, 265-274. [CrossRef]

13. Hiroki, S.; Garnevska, E.; McLaren, S. Consumer perceptions about local food in New Zealand, and the role of life cycle-based environmental sustainability. J. Agric. Environ. Ethics 2016, 29, 479-505. [CrossRef]

14. Scharber, H.; Dancs, A. Do locavores have a dilemma? Economic discourse and the local food critique. Agric. Hum. Values 2016, 33, 121-133. [CrossRef]

15. PRISMA 2020 Checklist. Available online: http://prisma-statement.org/documents/PRISMA_2020_checklist.pdf/ (accessed on 1 July 2021).

16. Chiffoleau, Y.; Dourian, T. Sustainable food supply chains: Is shortening the answer? A literature review for a research and innovation agenda. Sustainability 2020, 12, 9831. [CrossRef]

17. Montefrio, M.J.F.; De Chavez, J.C.; Contreras, A.P.; Erasga, D.S. Hybridities and awkward constructions in Philippine locavorism: Reframing global-local dynamics through assemblage thinking. Food Cult. Soc. 2020, 23, 117-136. [CrossRef]

18. Lim, K.H.; Hu, W.Y. How local is local? A reflection on Canadian local food labeling policy from consumer preference. Can. J. Agric. Econ. 2016, 64, 71-88. [CrossRef]

19. Xu, E.; Lee, T. Communicative and globalizing impacts of food labels: An Australian study. Media Int. Aust. 2020, 175, 93-108. [CrossRef]

20. Eriksen, S.N. Defining local food: Constructing a new taxonomy: Three domains of proximity. Acta Agric. Scand. Sect. B-Soil Plant Sci. 2013, 63, 47-55. [CrossRef]

21. Schmitt, E.; Barjolle, D.; Tanquerey-Cado, A.; Brunori, G. Sustainability comparison of a local and a global milk value chains in Switzerland. Bio-Based Appl. Econ. 2016, 5, 175-198.

22. Coelho, F.C.; Coelho, E.M.; Egerer, M. Local food: Benefits and failings due to modern agriculture. Sci. Agric. 2018, 75, 84-94. [CrossRef]

23. Bentsen, K.; Pedersen, P.E. Consumers in local food markets: From adoption to market co-creation? Br. Food J. 2020, $123,1083-1102$. [CrossRef]

24. Kwil, I.; Piwowar-Sulej, K.; Krzywonos, M. Local entrepreneurship in the context of food production: A review. Sustainability 2020, 12, 424. [CrossRef]

25. Rucabado-Palomar, T.; Cuellar-Padilla, M. Short food supply chains for local food: A difficult path. Renew. Agric. Food Syst. 2020, 35, 182-191. [CrossRef]

26. Morris, C.; Buller, H. The local food sector: A preliminary assessment of its form and impact in Gloucestershire. Br. Food J. 2003, 105, 559-566. [CrossRef]

27. Zhong, T.Y.; Si, Z.Z.; Shi, L.F.; Ma, L.; Liu, S.H. Impact of state-led food localization on suburban districts' farmland use transformation: Greenhouse farming expansion in Nanjing city region, China. Landsc. Urban Plan. 2020, 202, 103872. [CrossRef]

28. Michalský, M.; Hooda, P.S. Greenhouse gas emissions of imported and locally produced fruit and vegetable commodities: A quantitative assessment. Environ. Sci. Policy 2015, 48, 32-43. [CrossRef]

29. Carroll, B.E.; Fahy, F. Locating the locale of local food: The importance of context, space and social relations. Renew. Agric. Food Syst. 2015, 30, 563-576. [CrossRef] 
30. Boros, P.; Toth, Z.B.; Feher, O. The economic and marketing importance of local food products in the business policy of a Hungarian food retail chain. Procedia Soc. Behav. Sci. 2013, 81, 589-594. [CrossRef]

31. Tellstrom, R.; Gustafsson, I.B.; Mossberg, L. Local food cultures in the Swedish rural economy. Sociol. Rural. 2005, 45, 346-359. [CrossRef]

32. Nilsson, H. Local food systems from a sustainability perspective: Experiences from Sweden. Int. J. Sustain. Soc. 2009, 1, 347-363. [CrossRef]

33. Creamer, N.G.; Dunning, R.D. Local food systems for a healthy population. North Carol. Med. J. 2012, 73, 310-314. [CrossRef]

34. Nelligan, D.; Cameron, N.; Mackinnon, B.L.; Vance, C. Bridging gaps: A framework for developing regional food systems. J. Agric. Food Syst. Commun. Dev. 2016, 7, 49-69. [CrossRef]

35. Bakos, I.M.; Khademi-Vidra, A. Empirical experiences of the Hungarian alternative food buying communities. Deturope Cent. Eur. J. Reg. Dev. Tour. 2019, 11, 55-73.

36. Jung, S.E.; Shin, Y.H.; Dougherty, R. A multi theory-based investigation of college students underlying beliefs about local food consumption. J. Nutr. Educ. Behav. 2020, 52, 907-917. [CrossRef] [PubMed]

37. Tiemann, T. Grower only farmers markets: Public spaces and third places. J. Pop. Cult. 2008, 41, 467-487. [CrossRef]

38. Tregear, A. Progressing knowledge in alternative and local food networks: Critical reflections and a research agenda. J. Rural Stud. 2011, 27, 419-430. [CrossRef]

39. Feldmann, C.; Hamm, U. Consumers perceptions and preferences for local food: A review. Food Qual. Prefer. 2015, 40, 152-164. [CrossRef]

40. La Trobe, H. Farmers markets: Consuming local rural produce. Int. J. Consum. Stud. 2001, 25, 181-192. [CrossRef]

41. Schneider, M.L.; Francis, C.A. Marketing locally produced foods: Consumer and farmer opinions in Washington County, Nebraska. Renew. Agric. Food Syst. 2005, 20, 252-260. [CrossRef]

42. Hinrichs, C.C.; Allen, P. Selective patronage and social justice: Local food consumer campaigns in historical context. J. Agric. Environ. Ethics 2008, 21, 329-352. [CrossRef]

43. Guptill, A.; Wilkins, J.L. Buying into the food system: Trends in food retailing in the US and implications for local foods. Agric. Hum. Values 2002, 19, 39-51. [CrossRef]

44. Winter, M. Embeddedness, the new food economy and defensive localism. J. Rural Stud. 2003, 19, 23-32. [CrossRef]

45. Born, B.; Purcell, M. Avoiding the local trap scale and food systems in planning research. J. Plan. Educ. Res. 2006, 26, 195-207. [CrossRef]

46. Kemp, K.; Insch, A.; Holdsworth, D.K.; Knight, J.G. Food miles: Do UK consumers actually care? Food Policy 2010, 35, 504-513. [CrossRef]

47. Duvernoy, I. Alternative voices in building a local food policy: Forms of cooperation between civil society organizations and public authorities in and around Toulouse. Land Use Policy 2018, 75, 612-619. [CrossRef]

48. Baritaux, V.; Houdart, M.; Boutonnet, J.P.; Chazoule, C.; Corniaux, C.; Fleury, P.; Lacombe, N.; Napoleone, M.; Tourrand, J.F Ecological embeddedness in animal food systems (re-)localisation: A comparative analysis of initiatives in France, Morocco and Senegal. J. Rural Stud. 2016, 43, 13-26. [CrossRef]

49. Brodt, S.; Kramer, K.J.; Kendall, A.; Feenstra, G. Comparing environmental impacts of regional and national-scale food supply chains: A case study of processed tomatoes. Food Policy 2013, 42, 106-114. [CrossRef]

50. McWilliams, J.E. Just Food: Where Locavores Get it Wrong and How We Can Truly Eat Responsibly; Little, Brown and Company: New York, NY, USA, 2009; p. 18.

51. Saunders, C.; Barber, A. Carbon footprints, life cycle analysis, food miles: Global trade trends and market issues. Political Sci. 2008, 60, 73-88. [CrossRef]

52. Loke, M.K.; Xu, X.; Leung, P. Estimating organic, local, and other price premiums in the Hawaii fluid milk market. J. Dairy Sci. 2015, 98, 2824-2830. [CrossRef]

53. Berti, G.; Mulligan, C. Competitiveness of small farms and innovative food supply chains: The role of food hubs in creating sustainable regional and local food systems. Sustainability 2016, 8, 616. [CrossRef]

54. Pascucci, S.; Dentoni, D.; Lombardi, A.; Cembalo, L. Sharing values or sharing costs? Understanding consumer participation in alternative food networks. Njas-Wagening. J. Life Sci. 2016, 78, 47-60. [CrossRef]

55. He, C.Y.; Liu, R.F.; Gao, Z.F.; Zhao, X.; Sims, C.A.; Nayga, R.M. Does local label bias consumer taste buds and preference? Evidence of a strawberry sensory experiment. Agribusiness 2020. [CrossRef]

56. Shafieizadeh, K.; Tao, C.W. How does a menu's information about local food affect restaurant selection? The roles of corporate social responsibility, transparency, and trust. J. Hosp. Tour. Manag. 2020, 43, 232-240. [CrossRef]

57. Winterstein, J.; Habisch, A. Is local the new organic? Empirical evidence from German regions. Br. Food J. 2021. [CrossRef]

58. Lutz, J.; Smetschka, B.; Nelson, G. Farmer cooperation as a means for creating local food systems: Potentials and challenges. Sustainability 2017, 9, 925. [CrossRef]

59. Mgonja, J.T.; Backman, K.F.; Backman, S.J.; Moore, D.D.; Hallo, J.C. A structural model to assess international visitors perceptions about local foods in Tanzania. J. Sustain. Tour. 2017, 25, 796-816. [CrossRef]

60. Ayres, J.; Bosia, M.J. Beyond global summitry: Food sovereignty as localized resistance to globalization. Globalizations 2011, 8, 47-63. [CrossRef] 
61. Ilbery, B.; Maye, D. Food Supply chains and sustainability: Evidence from specialist food producers in the Scottish/English borders. Land Use Policy 2005, 22, 331-344. [CrossRef]

62. Brunori, G.; Galli, F.; Barjolle, D.; van Broekhuizen, R.; Colombo, L.; Giampietro, M.; Kirwan, J.; Lang, T.; Mathijs, E.; Maye, D.; et al. Are local food chains more sustainable than global food chains? Considerations for assessment. Sustainability $2016,8,449$. [CrossRef]

63. Tongarlak, M.H.; Lee, D.; Ata, B. Mechanisms for increasing sourcing from capacity-constrained local suppliers. Decis. Sci. 2017, $48,108-149$. [CrossRef] 